\title{
Scaling-up universal financial protection: experience from a tertiary health facility of the impact of perception on the willingness to enrol in health insurance schemes in Delta State, Nigeria
}

\author{
Ufuoma John Ejughemre \\ Delta State University Teaching Hospital, Department of Community Medicine, Oghara, Delta State, Nigeria \\ Correspondence: Ufuoma John Ejughemre. Address: Delta State University Teaching Hospital, Department of \\ Community Medicine, P.M.B 07, Oghara, Delta State, Nigeria. E-mail: ufuoma.ejughemre@delsuth.com.ng \\ Received: July 9, 2014 \\ Accepted: August 22, 2014 \\ Online Published: September 17, 2014 \\ DOI : $10.5430 /$ jha.v3n6p29 \\ URL: http://dx.doi.org/10.5430/jha.v3n6p29
}

\begin{abstract}
Objective: To assess the evidence of how the perception of health insurance impacts on the willingness to enrol and utilize health insurance among clienteles using tertiary health services.

Method: This was a descriptive cross-sectional study. The instrument was a pre-tested, semi-structured self administered questionnaire. Descriptive statistics as well as chi-square test and regression analysis were done to show statistically significant associations.

Results: The findings reveal that majority of the respondents, that is 109 (46.4\%) were of the opinion that health insurance is a viable programme, however they had their reservations, which were those of uncertainty, amongst others. Nevertheless, the perception by most of the respondents showed that they need more information based on their poor experiences of health insurance, and this strengthens their quest to enrol in any such scheme. A sufficiently reliable association between the feeling that they need more information on health insurance and the willingness to enrol in a health insurance scheme $\left(\chi^{2}=11.690, \mathrm{df}=1, p\right.$-value $\left.=.001\right)$ was shown.

Conclusion: The findings from this study has brought to the fore that perception of clients using health services impacts on their desire and willingness to participate in health insurance schemes. However, there are concerns that necessitate wide spread advocacy for health insurance.
\end{abstract}

\section{Key words}

Health insurance, Pre-payment, Perception, Enrolment, Health services, Nigeria

\section{I ntroduction}

Efforts by member states of the World Health Organization (WHO) towards improving health outcomes culminated in the Alma-ata declaration in $1978^{[1]}$. This became necessary following the recognition that challenges such as poor health care financing, poor public demand, inadequate utilization of health service facilities, inter alia facing health systems' of developing countries would hinder universal health coverage (UHC) ${ }^{[2]}$. So far there have been significant achievements in 
achieving the objectives of universal health coverage. Notwithstanding, the concerns on the subject of sustainable health care financing in many low-resource countries such as Nigeria continues to be a problem ${ }^{[3,4]}$. Actually, it remains progressively difficult to sustain satisfactory levels of financing healthcare as out-of-pocket spending (OOPS) remains the main mechanism for payment for most services ${ }^{[5]}$. In contrast to what is obtainable in developed countries, were various arrangements have been made for pre-payment and health insurance ${ }^{[6]}$, evidence reveals that the main payment method in these countries can be "catastrophic" in the sense of leading to or worsening poverty levels by reducing access to other necessary "goods" such as food, housing and clothing ${ }^{[7-9]}$. Whereas no clear answer exists to the question as to how much should be invested on healthcare (in fixed money terms or as a share of gross income), accordingly, measures have been taken to address this financing challenge.

These issues have in recent times necessitated the adoption of a number of policy measures in developing countries. Notable amongst these is that with the Nigerian government, were its health financing policy provides a framework for establishing pre-payment schemes within the context of the national health insurance scheme (NHIS) ${ }^{[10]}$. This is to expand cover in health care delivery for the formal and informal sectors as a strategy towards universal access to healthcare ${ }^{[9,11,12]}$. As a result; various health insurance schemes now exist in the country. Of such include the formal sector social health insurance programme (FSSHIP), community based health insurance and private health insurance schemes. However, health insurance as a financing mechanism remains rudimentary in many parts of the country. Nevertheless, these financing schemes are established to gather together resources for healthcare and at the same time protect enrollees in such schemes from financial risk they may be exposed to at the time of paying for health services ${ }^{[7,8]}$. There are reports that these schemes (health insurance) have had positive impacts on healthcare financing and healthcare outcomes, by

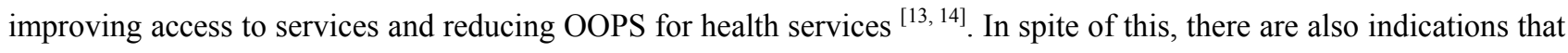
the perception of health insurance by members of the public could be a hindrance and the underlying limiting factor that has negatively affected the willingness to enrol in such schemes ${ }^{[12]}$. In fact, this is now a rising school of thought besides the problems of adverse selections, risk ratings, moral hazards, and other systematic problems in implementing these programmes in the country ${ }^{[15,16]}$. The argument therefore is that, although the national health insurance policy has been ratified with a view to its scaling-up, the perception of health insurance may constraint the scaling-up and utilization of health insurance packages in the country. Accordingly, the ongoing reforms of Nigeria's healthcare financing system necessitate periodic evaluation to ensure that it achieves the objectives of sustainable health financing and universal health coverage. Therefore, to provide evidence for health policy, this research then assesses the evidence of how the perception of health insurance impacts on the willingness to enrol and utilize health insurance among clienteles using tertiary health services. Specifically, the research question that will be addressed in this research is; how does perception of health insurance impact on the willingness to enrol and utilize health insurance schemes among clients utilizing tertiary health services, by using a tertiary health facility in Delta State, Nigeria. Consequently, it is hoped that the findings from this study should inform health policy and planning and constitute an important part of the base on which decisions on healthcare financing can be taken in the country and beyound.

\section{Methods}

To provide empirical evidence for policy, a descriptive cross-sectional study was conducted between the months of April to June, 2014. The study population consisted of out-patients in the general outpatient department (GOPD) in the Delta State University Teaching hospital Oghara; a tertiary health facility in a semi-urban community in Ethiope West Local Government Area of Delta State. Using the average clinical attendance rates per month, sample size estimation was determined using the formula, for estimating minimum sample size for descriptive studies when studying proportions with entire population size less than $10,000^{[13]}$. The calculated clinic attendance rate for the GOPD was 780 per month and a sample size of 257 was obtained. A simple random sampling technique was undertaken to sample 257 respondents from the GOPD of the hospital, however only 235 questionnaires were returned and analyzed. 
The study instrument was a pre-tested, semi-structured self-administered questionnaire. The questionnaire schedule elicited information in respect of the demographic characteristics of the respondents (age, sex, tribe, marital status, type of occupation). Some of the questions asked on perception towards health insurance included: (1) which statement is closest to your feeling about health insurance? (2) Do you feel that it is only those who can afford to pay for insurance that should benefit from it? (3) In your opinion, do you feel that you are poorly informed about health insurance schemes and as such need more information? On the willingness to enrol in a health insurance scheme questions included: (1) would you like to enrol in a health insurance scheme if made available to you? (2) What type of health insurance would you like to participate in if made available to you? (3) How much are you willing to contribute to a health insurance scheme regularly? The data generated were analyzed using statistical package for scientific solutions (SPSS 16.0 version). Descriptive statistics as well as chi-square test and regression analysis were used to assess the associations between variables, and the associations were considered significant at $p<.05$.

\section{Ethical approval}

The study was approved by the Health Ethics and Research committee of the Delta State University Teaching Hospital, Oghara and informed verbal consent was obtained from the participants.

\section{Results}

The results of the study were obtained from 235 clienteles visiting the general outpatient department of Delta State University Teaching Hospital.

\subsection{Demographic characteristics of respondents}

Findings from the study showed that the average age of the respondents was 36.95 years with a standard deviation of 15.601 . The majority of them were males $133(56.6 \%)$ with a male: female ratio of $1.3: 1$ and the majority of the respondents were single (53.2\%), with $44.7 \%$ being married and approximately $2.1 \%$ constituting divorced, co-habiting and widows. Findings of their occupational status revealed that a significant proportion of the respondents were unemployed at $45.1 \%$, and of those employed, those in the private sector were the majority at $28.5 \%$, government employees at $25.5 \%$ respectively. More so, the findings showed that most respondents $(60 \%)$ had attained one form of tertiary education, with only $4.7 \%$ who had no formal education (see Table 1 and 2 ).

Table 1. Demographic characteristics of respondents by gender and marital status

\begin{tabular}{lll}
\hline Characteristics & Frequency & Percentage (\%) \\
\hline Sex & & \\
Male & 133 & 56.6 \\
Female & 102 & 43.4 \\
Total & 235 & 100.0 \\
Marital Status & & \\
Single & 125 & 53.2 \\
Married & 105 & 44.7 \\
co-habiting & 4 & 1.7 \\
Others & 1 & 0.4 \\
Total & 235 & 100.0 \\
Mean Age of respondents (36.95) & Standard Deviation (15.601) & \\
\hline
\end{tabular}


Table 2. Characteristics of respondents by occupation and level of education

\begin{tabular}{lll}
\hline Occupation & Frequency & Percent (\%) \\
\hline government services & 60 & 25.5 \\
private & 67 & 28.5 \\
unemployed & 106 & 45.1 \\
Total & 235 & 100.0 \\
Level of Education & & \\
none & 11 & 4.7 \\
primary & 22 & 9.4 \\
secondary & 61 & 26.0 \\
tertiary & 141 & 60.0 \\
Total & 235 & 100.0 \\
\hline
\end{tabular}

\subsection{Perception of health insurance}

As illustrated in Table 3, the views of the respondents in the study revealed that they had diverse perceptions of prepayment (health insurance) as a mechanism for financing health care eservices. Findings from the study revealed that 109 $(46.4 \%)$ i.e. most of the respondents were of the opinion that health insurance would work, although they had their reservations in that it may be short lived (suggesting that it may not be a permanent programme) if started in various settings in the country, $11(4.7 \%)$ were indifferent while the others had other views including "negative" perceptions of health insurance. Additionally, 183 (77.9\%) i.e. most of the respondents felt that, affordability should be a criteria for enrolling and benefiting from health insurance packages. More so, most of the respondents were of the opinion that everybody should be entitled to one form of insurance irrespective of socio-economic background or any other differences. It was shown that $217(92.3 \%)$ were of the opinion that they were possible candidates to enrol and benefit from insurance schemes if made available. A chi-square analysis between the feeling that affordability and having paid income (i.e. having money to pay for insurance) was sufficiently reliable $\left(\chi^{2}=9.847, \mathrm{df}=1, p\right.$-value $\left.=.002\right)$ (see Table 4). More so, logistic regression analysis showed that the income level (those receiving payed income or not) contributed mainly to this perception of whom should enrol in a pre-payment scheme (health insurance) (those receiving payed income or not) $(\beta=$ $1.032, \mathrm{SE}=.404, p=.011)$ see Table 5 . This is irrespective of their financial status. Additionally, 172 (73.2\%) perceive that their current information (knowledge) of health insurance is insufficient with what they think they should know in order to benefit if made available, this is because most of them believe it is a better option to finance their health needs as against the norm (user-fees or out-of-pocket spending). These were the key findings from the respondents in the study.

Table 3. Distribution of respondents by perception of health insurance

\begin{tabular}{ll}
\hline Variables $\mathbf{( N}=\mathbf{2 3 5})$ & Frequency (\%) \\
\hline 1. Feeling towards health insurance & $33(14.0 \%)$ \\
-It is a waste of money & $44(18.7 \%)$ \\
-It cannot work properly in Nigeria & $38(16.2 \%)$ \\
-It is a government problem & $109(46.4 \%)$ \\
-believe that it is a viable programme & $11(4.7 \%)$ \\
-indifferent & \\
2. Should only those who can afford benefit from health insurance schemes & $52(22.1 \%)$ \\
-Yes & $183(77.9 \%)$ \\
-No & \\
3. Do you feel poorly informed about health insurance & $172(73.2 \%)$ \\
-Yes & $63(26.8 \%)$ \\
-No &
\end{tabular}

(Table continued on page 33) 
Table 3. (continued.)

\begin{tabular}{ll}
\hline Variables $(\mathbf{N}=\mathbf{2 3 5})$ & Frequency (\%) \\
\hline 4. Do you think that you have poor knowledge of health insurance and this can affect you & \\
from enrolling or benefiting from such schemes & $217(92.3 \%)$ \\
-Yes & $18(7.7 \%)$ \\
-No & \\
5. Do you think that you should be a candidate for health insurance schemes if available & $217(92.3 \%)$ \\
-Yes & $18(7.7 \%)$ \\
-No & \\
\hline
\end{tabular}

Table 4. Cross Tabulation between feeling of possible beneficiaries and having paid income

\begin{tabular}{|c|c|c|c|c|}
\hline & & \multicolumn{2}{|c|}{ Feel that those who afford insurance only should benefit } & \multirow{2}{*}{ Total } \\
\hline & & Yes & no & \\
\hline \multirow{2}{*}{ Do you have paid income currently } & Yes & 32 & 68 & 100 \\
\hline & No & 20 & 115 & 135 \\
\hline Total & & 52 & 183 & 235 \\
\hline
\end{tabular}

Note. $\mathrm{X}^{2}=9.847, \mathrm{df}=1, p$-value $=.002$

Table 5. Demographic characteristics and the perception of who should enrol in Health Insurance (Logistic Regression)

\begin{tabular}{lllllllll}
\hline Variables & B & S.E. & Wald & df & Sig. & Exp(B) & \multicolumn{2}{c}{ 95.0\% C.I. for EXP(B) } \\
\cline { 5 - 9 } age & -.019 & .014 & 1.881 & 1 & .170 & .981 & .954 & Lower \\
sex & .660 & .362 & 3.325 & 1 & .068 & 1.935 & .952 & 3.932 \\
marital & .502 & .387 & 1.684 & 1 & .194 & 1.652 & .774 & 3.527 \\
occupation & .044 & .246 & .032 & 1 & .857 & 1.045 & .645 & 1.695 \\
Level of education & .372 & .204 & 3.332 & 1 & .068 & 1.450 & .973 & 2.161 \\
Paid income & 1.032 & .404 & 6.536 & 1 & .011 & 2.808 & 1.272 & 6.195 \\
Constant & -2.576 & 1.401 & 3.383 & 1 & .066 & .076 & & \\
\hline
\end{tabular}

Note. Cox \& Snell R Square $=.087 ;$ Nagel kerke R Square $=.134$

\section{I mpact on enrolment in a health insurance scheme}

The study demonstrated the impact of perception towards clientele's desire to enrol and utilize health insurance as a financing mechanism for tertiary health services. Although insurance schemes are still rudimentary in this country, the increasing knowledge and varying perception seems to affect the demand for health insurance services. The study findings have thus revealed mixed views of the respondents' perception (feelings) towards health insurance or pre-payment for health care. The perception by most of the respondents showed that they need more information based on poor practical knowledge of health insurance and this strengthens their quest to enrol in any such scheme. An association of sufficient statistical reliability between the feeling that they need more information on health insurance and the willingness to enrol in a health insurance scheme $\left(\chi^{2}=11.690, \mathrm{df}=1, p\right.$-value $\left.=.001\right)$ was shown. The general view is that there is the need to enrol in one form of health insurance scheme. Significantly, most of the respondents have a preference to enrol in a social health insurance scheme (the national health insurance scheme, specifically), with it being perceived as the main option to enrol in by most of the respondents $(66.8 \%)$. Also, a significant number of the respondents (38.3\%) were willing to contribute up to and over $10 \%$ of their income as deductions towards health insurance. More so, the perception indicating the need for more "exposure" from such schemes by the study showed that perception impacts on individuals' acceptance and willingness to enrol and utilize the packages of insurance programmes if made available for healthcare. 


\section{Discussion}

The design of policy and the implementation of reforms in the health care sector requires well-founded and satisfactory estimates of the impacts of improvements in access and quality of care, and the extent to which these improvements can be financed by scaling-up adaptable financing mechanisms in the country. Notably, the ability of a client to pay for healthcare is an important determinant of accessibility to healthcare services, particularly tertiary health care which to a large extent depends on one's ability to pay at the point of service. Nevertheless, paying at the point of service or OOPS has been deemed retrogressive ${ }^{[14]}$. Of note is that the excessive reliance on this payment pattern (OOPS) decreases demand for healthcare, "scales-up" inequitable access to quality care, and exposes households to the financial risk of expensive illness at the time of need ${ }^{[15]}$. To this end, the ongoing large scale reforms of Nigeria's healthcare system necessitates periodic monitoring and evaluation to ensure achievement of the initial objectives aimed at sustainable health financing and universal health coverage ${ }^{[15]}$. Accordingly, this paper's aim is in its attempt to make available, evidence of the impact of perception of health insurance by clientele utilizing tertiary health services on their willingness to enrol in health insurance schemes so as to scale-up health care financing. In brief, the findings identified in the study provide evidence on the research question. Although the evidence is "narrow", nevertheless, several key themes were identified in this study.

Firstly, the findings from this study has brought to the fore a number of facts. It was revealed that the respondents had different views towards health insurance. 109 (46.4\%) i.e. most of the respondents were of the opinion that health insurance would be a viable health financing mechanism, notwithstanding they had their reservations. Issues that were highlighted by a number of respondents included; the fear of uncertainty, i.e. insurance programmes may not work even if they were instituted for would-be enrollees ( $18.7 \%$ of respondents), the perception that paying premiums is a waste of resources (14.0\%) especially if the required quality of health care cannot be guaranteed. Chiefly, it could be asserted that the challenges face the Nigerian health system such as incessant strike actions by health workers, unavailability of needed health equipments and in certain instances poorly skilled personnel working in public and private health facilities. These issues tend to decrease the quality of services that should be rendered and may have stirred up such feelings amongst these respondents. More so, it is important to consider that in a country like Nigeria, tertiary health care facilities are designed to provide specialized health care services. Evidence shows that poor quality and inadequacy of available services are reasons affecting access and utilization of services ${ }^{[17]}$. The import being that in the event of the availability of pre-payment, these factors could hinder the willingness to enrol in such a scheme. It is also possible that the high level of unemployment of the respondents at $45.1 \%$ could have accounted for the perception of uncertainty among the respondents. The fear of not being able to afford premiums could have accounted for these perceptions among some of the respondents. Additionally, negative perceptions (which were some of the experiences that evolved from the research) could arise from other factors such as the opinions of public figures in the society. Notably, in Ebonyi state where the FSSHIP (a strategy of the NHIS) was not implemented, members of the public reported the absence of positive reports from civil servants and top bureaucrats about the FSSHIP (which they considered more valuable than media adverts employed by the NHIS) ${ }^{[18]}$. In this situation, would-be enrollees (such as clienteles using tertiary health services) who are willing to participate in health insurance programmes didn't due to concerns raised by these opinion leaders.

In spite of these, there were positive gains from the respondents' views. Most of the respondents showed that they need more information based on their poor practical knowledge of health insurance, and this strengthens their quest to enrol in any such scheme if and when available. An association of sufficient statistical reliability between the feeling that they need more information on health insurance and the willingness to enrol in a health insurance scheme $\left(\chi^{2}=11.690, \mathrm{df}=1\right.$, $p$-value $=.001)$ was found. The import being that on the average most respondents may have their reservation but are willing to participate in one form of health insurance scheme. The argument is that the perceived gains outweigh any possible disadvantage. This suggests the need for more advocacies by policy makers at all levels to promote insurance and rapidly address the perception issues about health insurance in the country.

Secondly, there is also the concern that in spite of the evidence of the positive gains from the respondents' views, many people may not benefit from such if made available. The study brought to the fore, that a significant number of the 
respondents were unemployed and in the informal sector ( $45.1 \%$ and $28.5 \%$ respectively). It is possible that many wouldbe enrollees may never be enrollees. This stems from the fact that the FSSHIP still remains the major strategy employed by the government to scale-up health insurance, although there are reports of private and community based health insurance schemes (CBHIs) in the country, however evidence reveals that very few Nigerians are in any such schemes ${ }^{[19]}$. Unemployment and inability to pay despite the willingness to pay for such schemes are some of the growing concerns ${ }^{[20]}$. More so, it is also possible that cultural, language or other related factors may contribute to the perception of health insurance. However, these factors (particularly the tribe of the respondents) was observed to be a sensitive issue among respondents during the pilot phase of the study and as such was excluded from the study instrument used.

Similarly, the systemic challenges facing the insurance schemes may pose as problems to benefitting from this policy. Chiefly amongst these are the issues of inequity in health insurance, particularly is with community based health insurance schemes. Studies have shown that in spite of the willingness to pay for health insurance (community based health insurance schemes) which now serve as an alternative to the FSSHIP for the largely unskilled, unemployed, rural and semi-urban dwellers, there remain problems of adverse selection, poor community ratings and issues with solvency ${ }^{[21]}$. These are not quite the same for CBHIs such as seen in Tanzania, Cameroon, and the Masisi hospital pre-payment scheme in D.R. Congo ${ }^{[22]}$. Accordingly, promotion aimed at strengthening awareness and enrolment into health insurance schemes at all levels will be an answer to a number of the challenges. Furthermore, there is the need for financing arrangements through subsidies and donor support for community based health insurance schemes in the country ${ }^{[23]}$. This calls for all stake holders including international donors to support subsidies and continued research in the area of health financing, including community financing. The micro-health insurance strategy of the International Labour Organization STEP programme is such which will come to bear as a good example ${ }^{[24]}$.

\section{Conclusion}

The findings from this study has brought to the fore the fact that perception of health insurance among clients using health services impacts on their desire and willingness to participate in health insurance schemes. While there may be some wrong perceptions of pre-payment, the improving perception about health insurance will be beneficial to scaling-up health insurance. However, there are concerns with the designs and implementation of insurance schemes. Nigeria particularly needs to take steps to expand membership outside the formal sector, as has been more widely adopted in Ghana. The socioeconomic burdens and the variability in insurance provision across the country make it almost improbable to achieve universal coverage through pre-payment schemes in the near future. This necessitates wide spread advocacy at all levels, increased community participation and leveraging on available external support to expand health insurance in order to achieve universal health coverage through these schemes.

\section{Competing interests}

The author declares that he has no competing interests. The views and opinions expressed in this article are those of the author and do not reflect the official policy or position of any governmental agency.

\section{Acknowledgements}

The author is grateful to God Almighty for his inspiration, Dr P.G Oyibo for his encouragements all through the research, and the suggestions of the anonymous reviewers.

\section{References}

[1] WHO. 2000. The World Health Report 2000 Health Systems: Improving performance. Geneva: World Health Organization.

[2] World Bank. Health expenditure per capita [internet]. 2013. [cited 2013 Oct 10]. Available from:

http://data.worldbank.org/indicator/SH.XPD.PCAP. 
[3] Federal Ministry of Health Revised National Health Policy. Federal Ministry of Health (FMOH), Abuja, Nigeria. 2004.

[4] Musgrove P, Zaramdini R. A summary description of health financing in WHO member states. 2001. WHO/CMH Working Paper Series, Paper No. WG3:3. Geneva: World Health Organization.

[5] World Bank. Voices of the poor: can anyone hear us? Vol.1. Washington, DC: World Bank. 1999

[6] World Bank. World Development Report 2000/2001: Attacking poverty. Washington, DC: World Bank. 2000.

[7] World Bank. Innovations in health care financing. Proceedings from a World Bank Conference, March 10-11. Washington, DC: World Bank. 1997

[8] Mwabu G. Financing health services in Africa: An assessment of alternative approaches. Working Paper Series 0457.1990. Washington, DC: World Bank.

[9] Uzochukwu BSC. Health Care Financing, A review of the Nigerian Situation. Health Reform Foundation Scientific Meeting. 2012; 5-10.

[10] Asfaw, A., Gustafsson-Wright, E, Vander Gaag, J. Willingness to pay for health insurance: An analysis of the potential market for new low-cost health insurance products in Namibia, Amsterdam Institute for International Development. 2008; AIID RS - 08 01/2: $1-22$.

[11] Shimeles A. Community Based Health Insurance Schemes in Africa: the Case of Rwanda. African Development Bank Group. Working Paper. 2010; 120.

[12] Stinson, W. Potential and Limitations of Community Financing. World Health Forum. 1984; 5.

[13] Araoye MO. Research Methodology with Statistics for Health and Social Sciences. Ilorin: Nathadex Publishers. 2004; Sample size determination; 115-21.

[14] Oyibo PG. Out-of-pocket payment for health services: constraints and implications for government employees in Abakaliki, Ebonyi state, South east Nigeria. African Health Sciences. 2011; 11(3): 481-485. PMid: 22275943.

[15] Onoka C, Onwujekwe O, Uzochukwu BS, Ezumah N. Promoting universal financial protection: constraints and enabling factors in scaling-up coverage with social health insurance in Nigeria. Health Research Policy and Systems. 2013; 11: 20. PMid: 23764306. http://dx.doi.org/10.1186/1478-4505-11-20

[16] Banjoko SO, Banjoko, NJ, Omoleke IA. Knowledge and perception of telemedicine and E-health. Available at www.wikieducator.org. Accessed 15 February 2009.

[17] Soafer, S, Firminger, K. Patient's Perception of the quality of health services. Annual Review in Public Health. 2005 ; $26: 513-59$. PMid: 15760300. http://dx.doi.org/10.1146/annurev.publhealth.25.050503.153958

[18] Onoka C, Onwujekwe O, Uzochukwu BS, Ezumah N. Promoting universal financial protection: constraints and enabling factors in scaling-up coverage with social health insurance in Nigeria. Health Research Policy and Systems. 2013, 11: 20. PMid: 23764306. http://dx.doi.org/10.1186/1478-4505-11-20

[19] Uzochukwu BSC. Health Care Financing, A review of the Nigerian Situation. Health Reform Foundation Scientific Meeting. 2012; 5-10.

[20] Onwujekwe O., Onoka C, Uguru N., Nnenna T, Uzochukwu B., Eze S., et al. Preferences for benefit packages for community-based health insurance: an exploratory study in Nigeria. BMC Health Services Research. 2010; 10: 162. PMid: 20540787. http://dx.doi.org/10.1186/1472-6963-10-162

[21] Schoen C, Osborn R, Squires D, Doty MM, Pierson R, Applebaum S. How health insurance design affects access to care and costs, by income, in eleven countries. Health Aff (Millwood). 2010; 29: 2323-34. PMid: 21088012. http://dx.doi.org/10.1377/hlthaff.2010.0862

[22] Ekman, B. Community-based health insurance in low-income countries: a systematic review of the evidence. Health Policy and Planning. 2004; 19: 249-70. PMid: 15310661. http://dx.doi.org/10.1093/heapol/czh031

[23] Ejughemre U.J. Donor Support for Community Health Financing: Options and Opportunities for Sub-Saharan African Communities. American Journal of Public Health Research. 2013; 1(6): 129-13. http://dx.doi.org/10.12691/ajphr-1-6-1

[24] International Labour Organization, ILO/STEP. Methodological guide for undertaking case studies: health micro insurance schemes. Geneva: International Labour Organization. 2000. 